\title{
Present-day sea level rise: from satellite and in situ observations to physical causes
}

\author{
A. Cazenave, K. Do Minh and M.C. Gennero \\ LEGOS-GRGS/CNES, 18 av. Edouard Belin, 31401 Toulouse Cédex 9, France \\ anny.cazenave@cnes.fr
}

\begin{abstract}
We investigate climate-related processes causing variations of the global mean sea level on interannual to decadal time scale. We focus on thermal expansion of the oceans and continental water mass balance. We show that during the 1990s where global mean sea level change has been measured by Topex/Poseidon satellite altimetry, thermal expansion is the dominant contribution to the observed $3 \mathrm{~mm} / \mathrm{yr}$ sea level rise. For the past decade, exchange of water between continental reservoirs and oceans as well as glaciers and ice sheet melting may account to up $1 \mathrm{~mm} / \mathrm{yr}$. This suggests that there is a missing contribution which counterbalances the $1 \mathrm{~mm} / \mathrm{yr}$ eustatic contribution. Dam building and irrigation associated with anthropogenic activities appear able to cancel out the effect of ice melting and land water change. For the last four decades, thermal contribution is estimated to about $0.5 \mathrm{~mm} / \mathrm{yr}$, with a possible accelerated rate of steric sea level rise during the 1990s.
\end{abstract}

Keywords. Sea level, satellite altimetry, thermal expansion, land water, ice melting

\section{Introduction}

Present day sea level change is a topic of considerable interest in the context of the current debate on global climate change because of its potential impact on human populations living in coastal areas. From a purely scientific point of view, sea level change is an attractive research area because of its interdisciplinary character. In effect, measuring sea level change and studying processes causing sea level change involve fields such as ocean and atmospheric sciences, hydrology, glaciology, geophysics, geodesy, and remote sensing. This is so because sea level change integrates non-linear coupled responses of several components of the Earth's system, mainly oceans, atmosphere, ice sheets, land water reservoirs, mantle and crust .
This paper focuses on global sea level variations on a time span ranging from last decade to past century. On such time scales, two classes of processes are responsible for global sea level variations:

- Temperature and salinity variations of ocean waters causing water density (volume) change;

- Exchange of water between oceans and other surface reservoirs (ice sheets, mountain glaciers, and land water reservoirs) associated with the global water cycle, causing ocean mass change.

Sea level changes due to temperature and salinity variations are called steric while sea level changes resulting from addition or removal of water mass are called eustatic. The term "eustatic" is sometimes misused, some authors assuming that eustatic means uniform. Such a definition is wrong, and we will see below that whatever the process involved, sea level change is all but uniform.

Since the publication in mid-2001 of the chapter on Sea Level Change (Church et al., 2001) in the Third Assessment Report by the IPCC, a number of new results have been reported in the recent literature. These may be summarized as follow:

- sea level rise (SLR) measured during the 1990s by Topex/Poseidon satellite altimetry has approached 3 $\mathrm{mm} / \mathrm{yr}$, a value significantly larger than current estimates of the $20^{\text {th }}$ century SLR that re opens the question of SLR acceleration

- sea level change, whether steric or eustatic, is highly non uniform spatially

- land water mass contribution due to change of the global water cycle can now be estimated

- revised estimates of mountain glaciers and ice sheet melting are available for the past decade

We first discuss observations of sea level change (from satellite altimetry, and tide gauges, as well as from Earth's rotation and gravity field). Then we show that for the 1990s, SLR is fully explained by thermal expansion (warming) of ocean waters. Next We compare thermal expansion for the past 50 years to SLR measured by tide gauges and demonstrate that the $20^{\text {th }}$ century SLR is very likely over estimated by a factor of 2 . Continental waters contribution to SLR is also discussed, as well as 
recently published re estimates of ice sheet and glacier melting to SLR. Finally we discuss the possibility of a recent acceleration of the rate of SLR.

\section{Observed sea level change during the 1990s}

During the last decade, sea level has been continuously measured by satellite altimetry with very high precision, high spatio-temporal sampling and global coverage (e.g., Cazenave et al., 2003, Nerem and Mitchum, 2001a, Nerem and Mitchum, 2001b, Cazenave and Nerem, 2003). Fig. 1 shows the global mean sea level curve based on Topex/Poseidon for the period 1993-2003. The rate of SLR is $2.99 \pm 0.1 \mathrm{~mm} / \mathrm{yr}$.

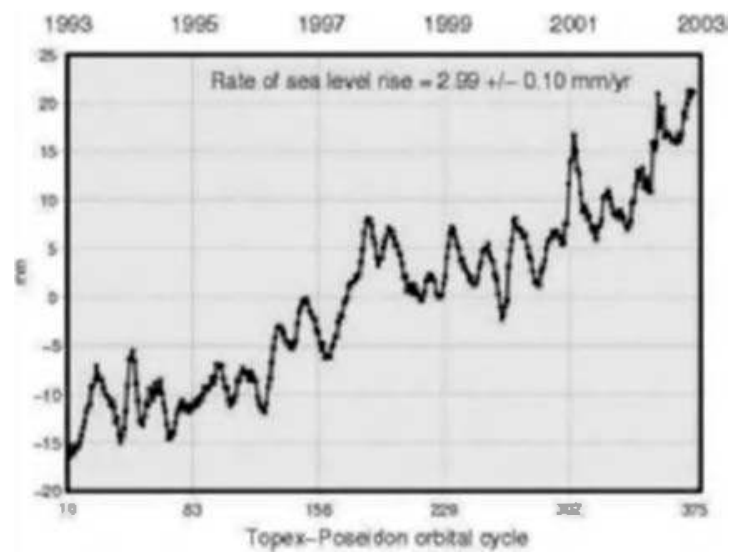

Fig. 1 Global mean sea level curve from Topex/Poseidon altimetry for 1993-2003.

Another important result of satellite altimetry is the mapping of the regional variability of sea level change (Fig. 2). Such a result was suspected before Topex/Poseidon but not yet demonstrated.

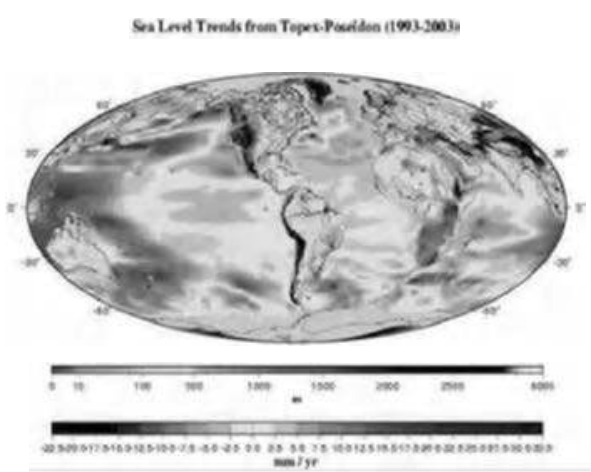

Fig. 2 Geographical distribution of sea level trends from Topex/Poseidon for 1993-2003.

\section{Sea level change during the previous decades from tide gauges observations}

Before the advent of the satellite altimetry, direct measurements of sea level change were (and are still) based on tide gauges. While current networks involve several hundreds of tide gauges, only very few tide gauges provide reliable historical records usable for sea level studies. Fig. 3 shows the location of the 27 tide gauges with records longer than 70 years, used by Douglas (2001) for re estimating the $20^{\text {th }}$ century SLR.

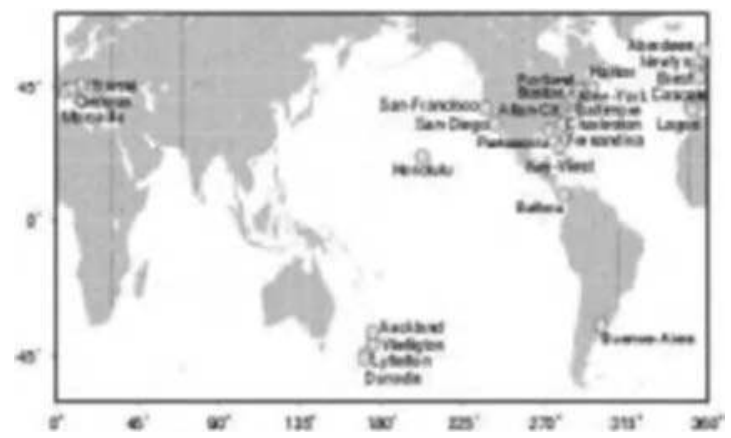

Fig. 3 Location of the 25 historical tide gauges used to estimate the 20 th century sea level rise.
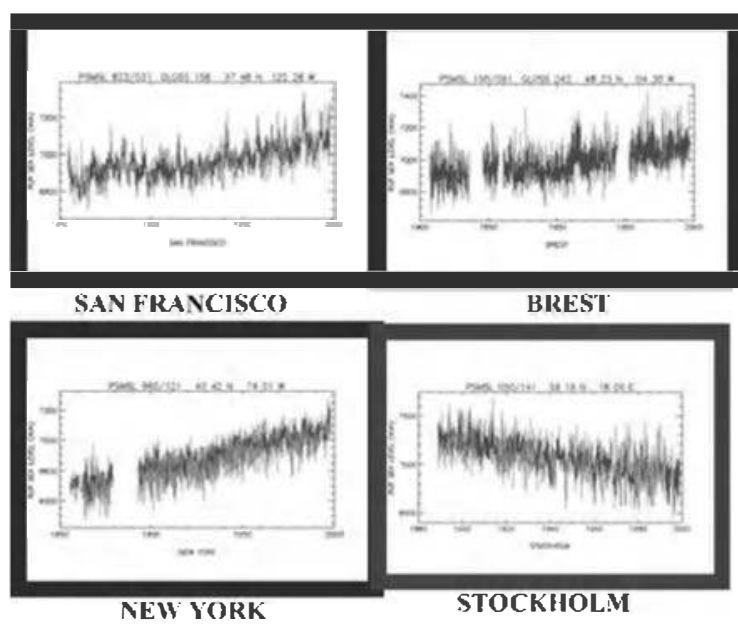

Fig. 4 Examples of tide gauge records at San Francisco, Brest, New York and Stockholm.

Fig.4 shows a few examples of tide gauges records. The Stockholm's record clearly illustrates one of the two main drawbacks of tide gauges (the second being heterogeneous and limited coverage), i.e., land motion contamination. At Stockholm (Sweden), tide gauges mostly measure Post Glacial Rebound (PGR), the vertical motion of the Earth's crust since last deglaciation. 
Many estimates of the $20^{\text {th }}$ century SLR have been published during the past 2 decades. Most recent estimates are:

- Douglas (2001) (27 tide gauges): $1.71+0.55$ $\mathrm{mm} / \mathrm{yr}$

- Peltier (2001) (same 27 tide gauges as Douglas, but correction for PGR): $1.85+0.35 \mathrm{~mm} / \mathrm{yr}$

- Tamiseia et al. 2001 (23 tide gauges included in the 27 Douglas' sites) : $1.5+0.4 \mathrm{~mm} / \mathrm{yr}$

- IPCC; Church et al. (2001) (compilation of publications from the past decade): $1.5 \pm 0.5$ $\mathrm{mm} / \mathrm{yr}$

As shown in Tamiseia et al. (2001), the dispersion of sea level trend estimates probably reflects regional variability in relative sea level. This variability may either result from land motion or from oceanographic sources (including the steric component). Table 1 summarizes the advantages and drawbacks of tide gauges for measuring the global mean sea level.

Table 1.

\begin{tabular}{ll}
\hline Advantages & Drawbacks \\
\hline - historical information & - heterogeneous and limited \\
(back to $\sim 1900$ ) & coverage \\
- useful for calibrating & - gaps in data records \\
altimetry systems & - land motion \\
& contamination \\
\hline
\end{tabular}

\section{Astronomical and geophysical observables able to constrain present- day eustatic SLR}

Several authors ( Peltier, 1998, Johnson and Lambeck, 1999, Sabadini and Vermeersen, 2002, Munk, 2002) have shown that temporal variations of Earth's rotation parameters (angular velocity and polar motion), as well as of some geodetic parameters (low degree harmonics of the gravity field) can offer independent constraints on the range of present-day eustatic SLR (i.e., water mass change in the ocean basins). These observables are : - The non-tidal Earth's rotation acceleration (or equivalently, length of day -LoD- secular decrease), based on eclipses observations during Antiquity, back to $500 \mathrm{BC}$, and historical period up to present days (amounting to $-0.6 \mathrm{~ms} / \mathrm{cy}$ over the past 2500 years, in terms of LoD)

- The secular decrease of the Earth's dynamical flattening (noticed $\dot{j}_{2}$ ) observed by geodetical satellites during the past 25 years (amounting to $3 \times 10^{-11} / \mathrm{yr}$ over the past 25 years)
- The secular motion of the Earth's rotation pole (true polar wander) towards Greenland ( $10 \mathrm{~m} / \mathrm{cy}$ during the past 100 years)

These three observations have been generally explained by Post Glacial Rebound. Indeed viscous mantle material flowing from low latitudes towards high latitudes in response to the last deglaciation that started about 18000 years ago, has caused change of the Earth's inertia tensor, in particular of the polar moment of inertia C. Because the Earth is deformable, its rotation rate and rotation axis adjust themselves in order to conserve angular momentum. In the absence of other torques, change in length of day (LoD) is directly proportional to any change in C. The dynamical flattening $\mathrm{J}_{2}$ represents the equatorial bulge of the Earth. As for LoD, any change of $\mathrm{J}_{2}$ is also proportional to a change of $\mathrm{C}$. An interesting and intriguing point is that observed secular changes in LoD and $\mathrm{J}_{2}$ provide numerically equal changes in $\mathrm{C}$, suggesting that both observables are independent measures of the same physical process on two different time scales : the past 2500 years and the past 25 years. Considering the very long time span (2500 years) under consideration, the best candidate is evidently PGR. By the way, models of Post Glacial Rebound developed during the past 2 decades by several investigators appear able to explain LoD and $\mathrm{J}_{2}$ variations, for values of the lower mantle viscosity (in the range $1-5 \times 10^{21} \mathrm{Pas}$ ) that also fit geological observations of Holocene sea level. However, observed secular decrease of $\mathrm{J}_{2}$ may also reveal surface mass redistribution, for example meltwater added into the oceans from melting of the ice sheets. Several investigators have recently explored the effect of accounting for present-day eustatic SLR caused by Antactica and Greenland melting, in addition to PGR. Secular changes in LoD and $\mathrm{J}_{2}$ may be explained by $\sim 1.5 \mathrm{~mm} / \mathrm{yr}$ eustatic SLR (due to $500 \mathrm{Gt} / \mathrm{yr}$ of Antarctica melting plus $140 \mathrm{Gt} / \mathrm{yr}$ Greenland melting), in addition to PGR, if the lower mantle viscosity is increased by an order of magnitude (thus in the range 1.-5. $\times 10^{22}$ Pas). This range value is not ruled out by global circulation models published during the past 15 years (using the observed long-wavelength geoid and seismic tomography models). However, mantle viscosity variation with depth is not tightly constrained. For example, a recent paper by Panyasuk and Hager (2000) shows that three rather different families of mantle viscosity profiles are typically derived from these global circulation models, depending on the type of tomography model used. At this stage, all what we can say is that the higher lower viscosity mantle required to explain the $\mathrm{J}_{2}$ secular decrease in 
terms of PGR plus a $\sim 1 \mathrm{~mm} / \mathrm{yr}$ eustatic SLR, is not incompatible with other geophysical observables. But it is also clear that we cannot use this observation to constrain the amount of present-day meltwater reaching the oceans. Concerning the true polar wander, it appears that a $1.5 \mathrm{~mm} / \mathrm{yr}$ eustatic SLR contribution significantly degrades the consistency between observed and predicted motion -both in amplitude and direction- (e.g., Sabadini and Vermeersen, 2002). In fact, it cannot be excluded that present-day true polar wander partly results from totally different phenomena, for example mantle convection and mantle avalanches across the lower mantle.

\section{Sea Level Rise : Do we really understand what we measure?}

\subsection{Sea level rise during the 1990s}

We now show that most of the sea level rise signal reported by Topex/Poseidon is of steric origin. Recently, S. Levitus and co-workers from NOAA provided a global gridded data set of ocean temperatures down to $3000 \mathrm{~m}$, for the past 50 years (Levitus et al., 2000a). This data set consists of $1^{\circ} \times 1^{\circ}$ gridded temperature fields derived from objective analyses of historical profiles, given as yearly means for the upper $500 \mathrm{~m}$ for 1945-1998 and as 5-years means for depths down to $3000 \mathrm{~m}$ for 1945-1996. Using the Levitus et al. temperature data set, Cabanes et al. (2001) computed the steric sea level contribution to the Topex/Poseidonderived SLR during the 6-year (1993-1998) of overlap of the two data sets. Fig. 5 compares sea level trend maps based on Topex/Poseidon and in situ ocean temperature data. The agreement between the two maps is striking. The dominant trend patterns seen in the Topex/Poseidon map are well reproduced in the steric trend map. The only region where the two maps are not in agreement is the southern oceans, probably a result of scarce temperature data in these remote regions.

Comparing the geographically averaged sea level time series (observed and steric) also shows remarkable agreement (Fig. 6). This result indicates that during 1993-1998, the $3 \mathrm{~mm} / \mathrm{yr}$ SLR observed by Topex/Poseidon is essentially due to warming of the world oceans. It also indicates that eustatic contributions are either negligible or cancel out each other.

\subsection{Sea level rise during the 20th century}

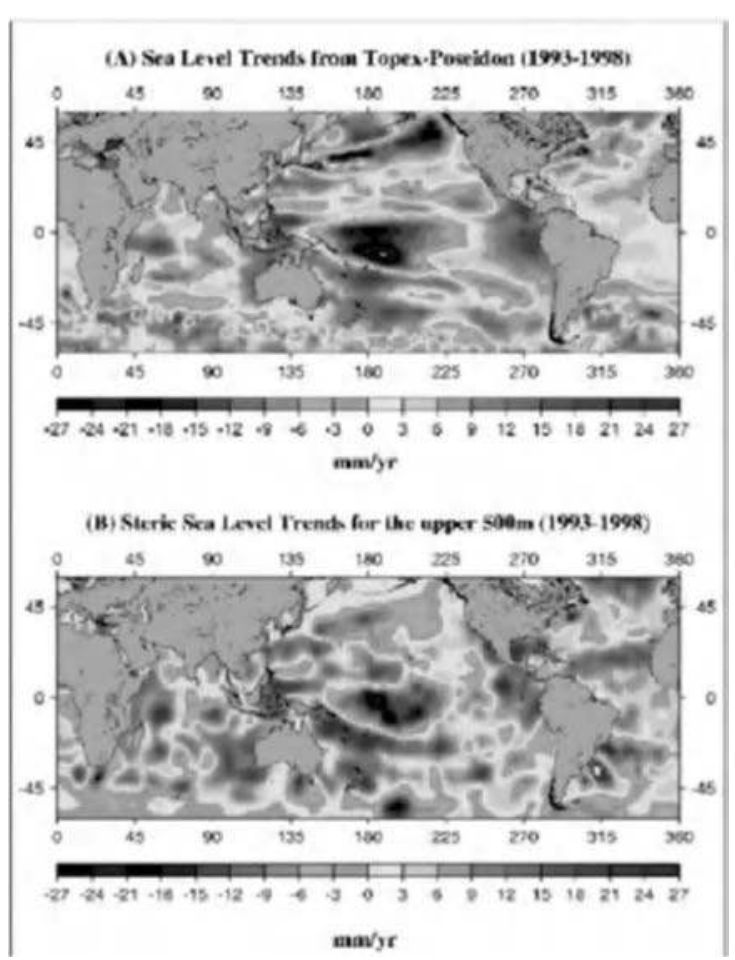

Fig. 5 (a) Sea level trend map from Topex/Poseidon for 19931998 (b) Steric sea level trend map for 1993-1998, computed from the Levitus et al.'s (2000a) temperature data set down to $500 \mathrm{~m}$.

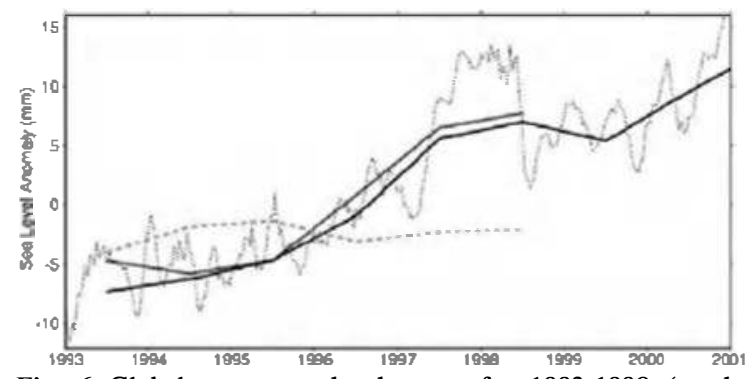

Fig. 6 Global mean sea level curve for 1993-1998 (yearly means) : observed from Topex/Poseidon (blue curve); steric contribution (red curve); residuals (green dashed curve).

The chapter on sea level change (Church et al., 2001) of the IPCC Third Assessment Report re evaluates climate-related contributions to the $20^{\text {th }}$ century sea level rise. The largest positive contribution $(0.5 \mathrm{~mm} / \mathrm{yr}$ of sea level rise) based on Ocean General Circulation Models (OGCMs) arises from thermal expansion due to warming of the oceans that mainly occurred since the 1950s. Melting of continental glaciers produces 0.2 to 0.4 $\mathrm{mm} / \mathrm{yr}$ sea level rise. Estimated Greenland and Antarctica mass imbalance (accounting for a longterm readjustment since Last Glacial Maximum plus a climate-related response) contributes -0.2 to 
$0.6 \mathrm{~mm} / \mathrm{yr}$. The least certain contribution is the change in terrestrial water storage that results from human activities, which is in the range of -1.1 to $+0.4 \mathrm{~mm} / \mathrm{yr}$ with a median value of $-0.35 \mathrm{~mm} / \mathrm{yr}$ (i.e., corresponding to sea level drop). The sum of these contributions ranges from -0.8 to $2.2 \mathrm{~mm} / \mathrm{yr}$, with a median value of $0.7 \mathrm{~mm} / \mathrm{yr}$. As we have seen, values for the $20^{\text {th }}$ century sea level rise based on tide gauges records are in the range $1.5-2 \mathrm{~mm} / \mathrm{yr}$. The IPCC report adopts as best estimate a value of $1.5 \pm 0.5 \mathrm{~mm} / \mathrm{yr}$ and notes that the sum of climaterelated components is low compared with the observational estimates. In effect, the observed value is more than twice as large as the revised estimate of the total climate contributions, although there is complete overlap between their respective uncertainties. It thus appears that either the climaterelated processes causing sea level rise are underestimated or sea level rise observed with tide gauges is biased toward values too high. We discuss below the two possibilities. We first show that the $1.5 \mathrm{~mm} / \mathrm{yr} 20^{\text {th }}$ century sea level rise could over estimated.

\subsection{Tide gauge bias}

Using the Levitus et al. (2000a) temperature data set, Cabanes et al. (2001) computed the steric contribution to SLR for the past 50 years. Fig. 7 shows the steric sea level trend map while Fig. 8 shows the steric sea level curve for 1955-1995. The mean trend amounts to $0.5 \pm 0.05 \mathrm{~mm} / \mathrm{yr}$, a value in very good agreement with IPCC's estimate mainly based on OGCMs. The effect of salinity is not taken into account in this estimate. However, a recent study by Antonov et al. (2002) indicates that in terms of global mean, salinity does not account for more than $0.05 \mathrm{~mm} / \mathrm{yr}$ (10\% of the thermal SLR) for the past 50 years SLR, even if salinity may be regionally important. The steric sea level trend map for the past 50 years displays important regional variability. On Fig. 7 are reported the 25 out if the 27 tide gauge sites (grouped into 9 regions) used by Douglas (2001) to estimate the $20^{\text {th }}$ century sea level rise. We immediately see that the heterogeneous and limited coverage of historical tide gauge networks cannot capture the regional variability. In other words, deriving a 'global mean sea level rise' by averaging geographically poorly distributed tide gauges data cannot lead to a meaningful estimate of the global average.

Cabanes et al. (2001) tested this hypothesis in computing a pseudo 'global mean' steric sea level by sub sampling the global thermosteric sea level grids at locations close to the 25 tide gauge sites of
Douglas. The pseudo 'global mean' steric sea level time series is superimposed to the 'true' global mean on Fig. 8. The linear trend of this pseudo 'global mean' amounts to $1.3+/-0.10 \mathrm{~mm} / \mathrm{yr}$, a value more than 2 times larger than the 'true' global mean trend (of $0.5+/-0.05 \mathrm{~mm} / \mathrm{yr}$ ). Looking at Fig.7, we indeed note that 23 out of the 25 sites are located in positive trend regions, thus fail to correctly sample the global mean variation.

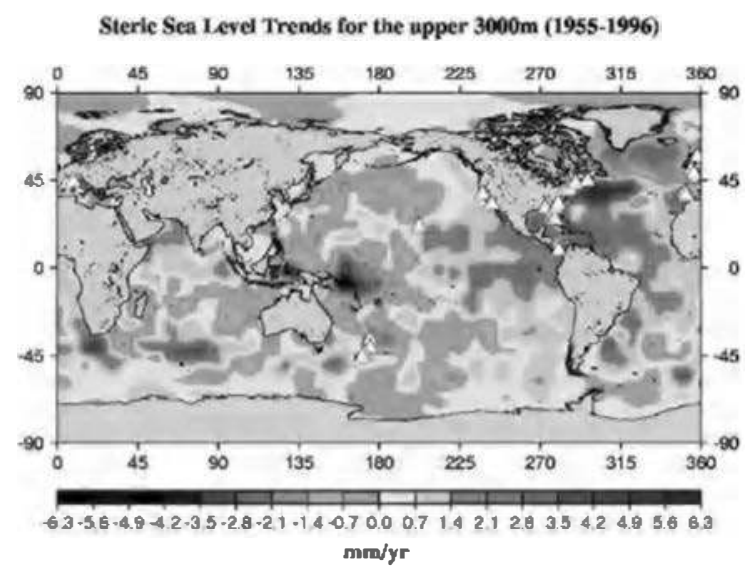

Fig. 7 Steric sea level trend map for 1955-1995, computed using the Levitus et al.'s (2000a) temperature data set down to $3000 \mathrm{~m}$. The 25 historical tide gauge sites are indicated by white triangles.

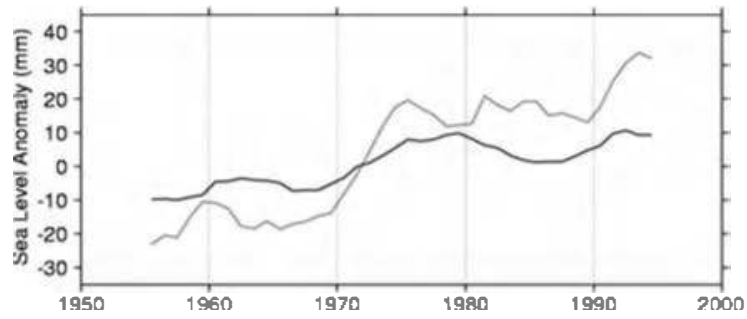

Fig. 8 Global mean steric sea level (red curve) for 1955-1995; 'pseudo global' mean steric sea level sub sampled at the 25 tide gauge sites (green curve) for 1955-1995.

To check whether the computed steric sea level rise correctly reproduces the observed tide gaugederived sea level rise, Cabanes et al. (2001) considered tide gauges records from the Permanent Service for Mean Sea Level (PSMSL) at the 25 sites. All records were corrected for the inverted barometer response of sea level to atmospheric forcing and Post Glacial Rebound with Peltier (1998) model (see Cabanes et al., 2001 and Cabanes, 2003 , for details). The 'average' tide gauge-derived sea level curve over 1955-1996, after performing regional grouping, is shown in Fig. 9 superimposed to the 'pseudo global' mean steric sea level. The observed (i.e., tide gauge-derived) mean sea level rise over $1955-1996$ amounts to $1.6+/-0.15 \mathrm{~mm} / \mathrm{yr}$, 
a value that agrees well with the pseudo 'global mean' steric rise $(1.3+/-0.10 \mathrm{~mm} / \mathrm{yr})$. The above results suggest that the limited and uneven tide gauges distribution produces a serious bias affecting global mean sea level rise estimates. Sub sampling the steric sea level for the past 50 years at the 287 sites of the GLOSS network implemented during the 1990s gives on the other hand a very good agreement with the true global mean (Cabanes, 2003). This confirms the importance of a uniform distribution of tide gauges for global sea level studies. From this discussion we conclude that current estimates of the $20^{\text {th }}$ century SLR may be too high. A value around $1 \mathrm{~mm} / \mathrm{yr}$ is probably closer to reality.

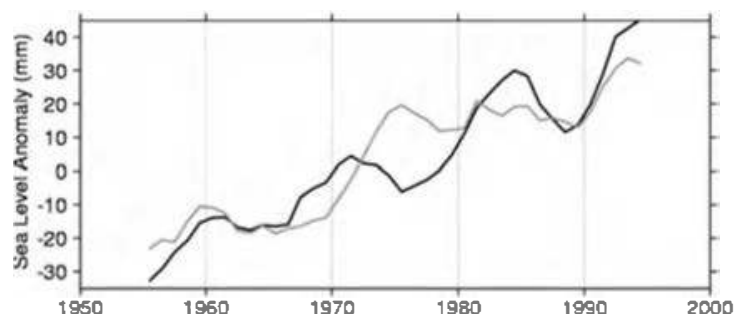

Fig. 9 'Pseudo global' mean steric sea level sub sampled at the 25 tide gauge sites (green curve) for 1955-1995; Observed mean sea level at the 25 tide gauges sites (blue curve) for 1955-1995.

\subsection{Eustatic contributions due to continental water reservoirs}

We now consider another eustatic contribution to SLR not taken into account by the IPCC: the land water mass contribution due to fluctuations of the global water cycle. Indeed, sea level is expected to change in response to the amount of water mass exchanged between oceans and land reservoirs under climate variability. Up to now, such an estimate has been hindered by the lack of global data on continental water storage. Continental water budget includes water (both liquid and solid) stored in the root-zone (soil moisture) and underground aquifers, in the snow pack and surface water reservoirs (lakes, rivers and wetlands). In terms of water mass change on interannual and decadal time scales, the largest contributions arise from soil moisture, ground waters and snow. The global distribution of these quantities is unknown over most of the world because in situ observations do not exist. Thus, global estimates of land water storage essentially rely on hydrological models, either coupled with atmosphere/ocean global circulation models, or forced by observations. The models estimate the variation in land water storage by solving a water budget equation that relates temporal change in land water mass to precipitation, evapostranspiration and runoff. In a forced mode, these land surface schemes are driven by spatiotemporally varying mass and energy fluxes, the main forcing being precipitation. Model outputs include gridded time series of soil moisture, snow depth, surface runoff, occasionally groundwater. While most models focus on the seasonal cycle, a few of them provide information on the interannual variability. A recent study by Milly et al.(2003) uses global land water data from the Land Dynamics model developed by Milly and Shmakin (2002) (a 'state-of-the-art' global hydrological model providing global grids of soil and underground waters and snow over 1981-1998), to estimate the land water mass contribution to sea level change during the last two decades. Fig. 10 shows the total contribution of underground water, soil water, and snow (seasonal terms removed), expressed in sea level equivalent. The total land water mass change contributes to a mean sea level rise of $0.15 \mathrm{~mm} / \mathrm{yr}$. This positive sea level trend indicates that, on the average, continental areas have become drier during the past two decades. This result appears correlated with an average decrease of precipitation over land, especially over large tropical river basins.

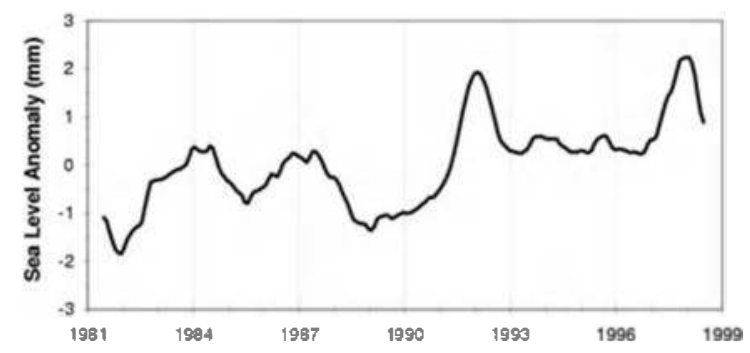

Fig. 10 Contribution to the global mean sea level of the sum of ground waters, soil moisture and snow for 1981-1998 (based on the Land Dynamics model).

\subsection{Eustatic contributions due to mountain glaciers and ice sheets}

There are two other sources of eustatic SLR: melting of mountain glaciers and melting of the ice sheets. Contribution of mountain glaciers melting is difficult to estimate on a global scale. However, all investigations conclude to a positive contribution (i.e., glacier melting) to the $20^{\text {th }}$ century sea level 
change, in the range of $0.2-0.3 \mathrm{~mm} / \mathrm{yr}$. Recent papers by Dyugerov and Meier (2002), and Meier and Wahr (2002) suggest that this contribution may have grown up to $0.5 \mathrm{~mm} / \mathrm{yr}$ in the recent years. Such a result is partly based on the very first estimate of Alaska glaciers melting by Arendt et al. (2002), contributing to $0.27 \pm 0.10 \mathrm{~mm} / \mathrm{yr}$ sea level rise over the past 35 years, with a clear acceleration during the 1990s. Although these estimates are still uncertain, it is not unreasonable to assume that glacier melting has accounted for up to $0.5 \mathrm{~mm} / \mathrm{yr}$ eustatic sea level rise during the 1990s.

Effects of Greenland and Antarctica melting/accumulation are also uncertain. IPCC values for present-day melting/accumulation are + $0.05 \mathrm{~mm} / \mathrm{yr}$ for Greenland and $-0.1 \mathrm{~mm} / \mathrm{yr}$ for Antarctica, plus a long-term readjustment since Holocene deglaciation, of $0.25 \mathrm{~mm} / \mathrm{yr}$. This longterm contribution is subject to controversy however. Some authors consider that ice sheet melting completely stopped 4000 years ago, implying a zero long-term contribution, while other authors do not support this point of view and conclude to a 0.25 $\mathrm{mm} / \mathrm{yr}$ long-term SLR on the basis of geological observations.

$\mathrm{mm} / \mathrm{yr}$. It is important to mention that this value mostly refers to recent (last decade) observations and cannot be extrapolated to the whole $20^{\text {th }}$ century. The above recent results raise the following question : since the Topex/Poseidon-derived sea level rise is almost totally explained by thermal expansion, there is no room for an additional 1 $\mathrm{mm} / \mathrm{yr}$ eustatic contribution unless the latter contribution is counter-balanced by a negative component (sea level drop). The only plausible candidate able to account for sea level drop is land water storage that results from human activities (construction of dams for production of hydroelectric energy, diversion of rivers for irrigation, land water use for urbanization, etc.). This component is very poorly known but has been probably close to zero; E. Rignot, personal communication). The total ice sheets effect leads to $\sim+0.3 \pm 0.01 \mathrm{~mm} / \mathrm{yr}$ present-day SLR. Summing up the three eustatic contributions $(0.15 \mathrm{~mm} / \mathrm{yr}$ for the land water component, $0.3 \mathrm{~mm} / \mathrm{yr}$ for presentday melting of Greenland and Antarctica, and 0.5 $\mathrm{mm} / \mathrm{yr}$ for mountain glaciers melting) leads to a total 'present-day eustatic' SLR approaching $\sim 1$ can be summarized as follows in terms of SLR:

Greenland $(+0.13 \mathrm{~mm} / \mathrm{yr})$, West Antarctica (+0.16 $\pm 0.05 \mathrm{~mm} / \mathrm{yr}$ ), East Antarctica (unknown, but estimated in the range of -1.1 to $+0.4 \mathrm{~mm} / \mathrm{yr}$ by the IPCC (2001), with a negative median value of 0.35 sheets based on various types of remote sensing measurements conducted during the 1990s. These $\mathrm{mm} / \mathrm{y}$ (i.e., sea level drop). In a recent study, recent estimates of the mass balance of the ice Gornitz (2001) has re evaluated sea level change induced by anthropogenic processes. Some effects such as

urbanization, ground water mining and Concerning present-day melting/accumulation of the ice sheets, Rignot and Thomas (2002) report deforestation lead to runoff increase, hence sea level rise. Other effects such as dam construction and irrigation produce runoff decrease, hence sea level drop. The latter two effects are by far the dominant contribution, so that according to Gornitz (2001) the net effect of human activities for recent decades is a sea level drop of $-0.9+/-0.45 \mathrm{~mm} / \mathrm{yr}$, exactly of the right order of magnitude to counterbalance the $+1 \mathrm{~mm} / \mathrm{yr}$ sea level rise due to recent ice sheet and glacier melting! While this result appears interesting, it needs to be confirmed by more precise determinations of the anthropogenic effects on the continental water cycle, thus ultimately on sea level change.

\section{Has sea level rise accelerated in the past 1-2 decades?}

We have seen above that the $20^{\text {th }}$ century sea level rise may have been over estimated, and that the true value is possibly closer to $1 \mathrm{~mm} / \mathrm{yr}$ than 2 $\mathrm{mm} / \mathrm{yr}$. We have also shown that for the past decade, SLR (based on Topex/Poseidon) amounts up to nearly $3 \mathrm{~mm} / \mathrm{yr}$. Has SLR accelerated recently? This is a serious possibility that needs to be investigated.

We have seen that during the 1990s thermal expansion fully explains the Topex/Poseidonderived SLR and that the positive eustatic contribution due to mountain and ice sheet melting and change in land water storage, is cancelled by a egative contribution, possibly of anthropogenic origin.

Fig. 11 shows the steric sea level curve for the past 50 years on which is superimposed sea level observed by Topex/Poseidon during the 1990s. It clearly appears that steric SLR has accelerated in the recent years. Fig. 12 presents steric sea level curves computed with ocean temperature data down to $500 \mathrm{~m}$ and $3000 \mathrm{~m}$ for latitude bands of $30^{\circ}$. We see that in several regions, steric sea level rise has accelerated around the early 1990s (and also in the early 1970s). Investigation ocean basin by ocean basin indicates that this behavior originates in the Atlantic ocean, in agreement with Levitus et al. 


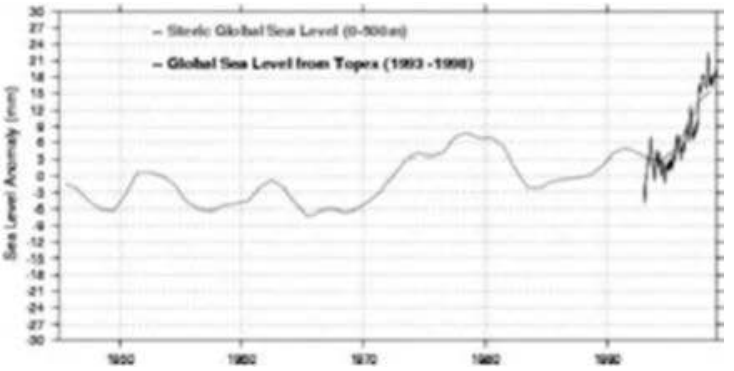

Fig. 11 Global mean steric sea level for 1955-1998 computed from the Levitus et al.'s (2000a) temperature data set down to $500 \mathrm{~m}$ (red curve); Topex sea level superimposed (black curve).

(2000b) results indicating that warming of the world ocean during the past 50 years was mostly effective in the Atlantic ocean.

\section{Perspectives}

Considering the potentially disastrous consequences of rising sea level in highly populated low altitude coastal regions, it is crucial to continue to precisely monitor sea level variations as well as better understand their causes. This is of high importance for improving sea level predictions for the 21th century, which according to the IPCC recent report are still very uncertain. Jason-1, the successor of Topex/Poseidon has been launched in December 2001 and already provides very precise sea level measurements. In March 2002 has been launched the GRACE mission which objective is to measure spatio-temporal variations of the gravity field with an unprecedented accuracy and resolution, on time scales ranging from one month to several years. The main application of GRACE is to monitor the redistribution of water mass among the surface fluid envelopes, i.e., changes of ocean water mass, continental water storage, including mountain ice and snow pack, and the ice sheets mass balance. GRACE over the continents will provide us with a precise estimate of the total land water mass contribution to sea level change while GRACE over the oceans will allow determination of water mass addition/removal into/from ocean basins. Finally combining GRACE data and Jason-1 data over the oceans will allow separation between thermal and mass effects. This will represent a great step towards a better understanding of various factors responsible for present-day sea level change.
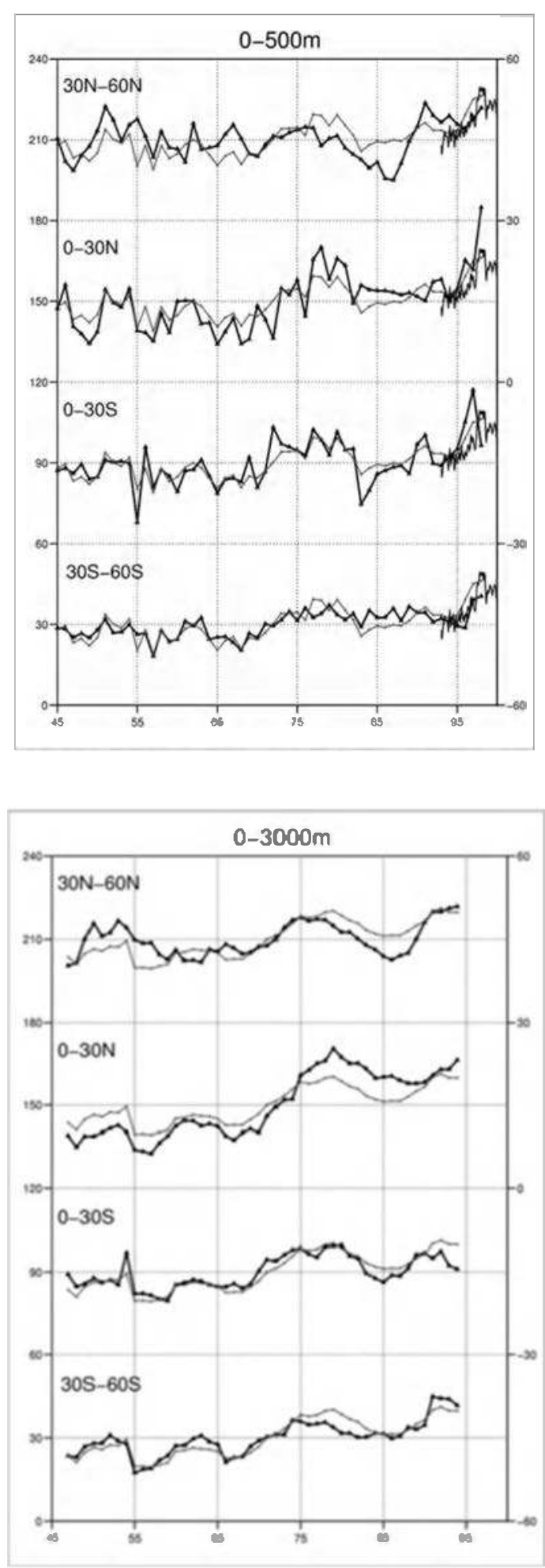

Fig. 12 Steric sea level curves as a function of latitude. (a) using temperature data down to $500 \mathrm{~m}$; (b) using temperature data down to $3000 \mathrm{~m}$. On both figures, the black curves are the latitudinal steric sea level while the red curve represents the global mean. The blue curve on Fig.12a is the observed Topex/Poseidon sea level. 


\section{References}

Antonov, J. J., S. Levitus and T. P. Boyer (2002). Steric Sea Level Variations during 1957-1994, Importance of Salinity, J Geophys Res, 107, 8013.

Arendt A. A., K. A. Echelmeyer, W. D. Harrison, C. S. Lingle and V. B. Valentine (2002). Rapid Wastage of Alaska Glaciers and Their Contribution to Rising Sea Level, Science, 297, pp. 382-386.

Cabanes, C., A. Cazenave and C. Le Provost (2001). Sea Level Rise during Past 40 Years Determined from Satellite and in Situ Observations, Science, 294, pp. 840-842.

Cabanes, C. (2003). Les Variations Du Nvieau Moyen Global et Regional De La Mer: Observation Par Altimetry Satellitale et Marégraphie, Analyse et Interpretation Physique. Thesis, Toulouse University.

Cazenave, A., C. Cabanes, K. Dominh, M. C. Gennero and C. Le Provost (2003). Present-Day Sea Level Change : Observations and Causes, Space Science Rev, 00, pp. 1-14.

Cazenave, A., and S. Nerem (2003). Present-Day Sea Level Change: Observations and Causes, Submitted to Rev Geophys.

Church, J., et al. (2001). Changes in Sea Level, In Climate Change 2001, The Scientific Basis. Contribution of Working Group I to the Third Assessment Report of the Intergovernmental Panel on Climate Change, J.T. Houghton et al., Eds, Cambridge Univ. Press, Cambridge.

Douglas, B. C. (2001). Sea Level Change in the Era of the Recording Tide Gauge, In Sea Level Rise, History and Consequences, B.C. Douglas, M. S. Kearney, S. P. Leartherman, Int Geophys Series, 75, pp. 37-64.

Gornitz, V. (2001). Impoundment, Groundwater Mining, and Other Hydrologic Transformations: Impacts on Global Sea Level Rise, In Sea Level Rise, History and Consequences, B. C. Douglas, M. S. Kearney, S. P. Leartherman, Int Geophys Series, 75, pp. 97-119.

Johnston, P., and K. Lambeck (1999). Postglacial Rebound and Sea Level Contributions to Changes in the Geoid and Earth's Rotation Axis, Geophys, J Int, 136, pp. 537-558.

Levitus, S., C. Stephens, J. I. Antonov and T. P. Boyer (2000a). Yearly and Year-Season Upper Ocean Temperature Anomaly Fields, 1948-1998, NOAA Atlas NESDIS 40, U.S. Gov. Printing Office, Wash., D.C., pp. 23.

Levitus, S., J. I. Antonov, T. P. Boyer and C. Stephens (2000b). Warming of the World Ocean, Science, 287, pp. 2225-2229.

Dyugerov, M. B., and M. F. Meier (2002). How Alaska Affects the World, Science, 297, pp. 350-351.

Meier, M. F., and J. M. Wahr (2002). Sea Level Is Rising : Do We Know Why, PNAS, 99, pp. 6525-6526.

Milly, P. C. D., and A. B. Shmakin (2002). Global Modelling of Land Water and Energy Balances: 1. The Land Dynamics (Lad) Model, J Hydrometeoroly, 3, pp.283-299.

Milly, P. C. D., A. Cazenave and M. C. Gennero (2003). Contribution of Climate-Driven Change in Continental Water Storage to Recent Sea Level Rise, Submitted to PNAS.

Munk, W. (2002). Twentieth Century Sea Level: An Enigma, PNAS, 99, pp. 6550-6555.

Nerem, R. S., and G. T. Mitchum (2001a). Observation of Sea Level Change from Satellite Altimetry, In Sea Level Rise, History and Consequences, B. C. Douglas, M. S. Kearney, S. P. Leartherman, Int Geophys, 75, pp. 121-163.

Nerem, R. S., and G. T. Mitchum (2001b). Sea Level Change. In Satellite Altimetry and Earth Sciences, A Handbook of Techniques and Applications, Fu, L. L., A. Cazenave Eds, Vol 69 of Int Geophys Series, Academic Press, pp. 329-349.

Panasyuk, S. V., and B. H. Hager (2000). Inversion for Mantle Viscosity Profiles Constraines by Dynamic Topography and the Geoid, and Thier Estimated Errors, Geophys J Int, 143, pp. 821-836.
Peltier, W. R. (2001). Global Glacial Isostatic Adjustment and Modern Instrumental Records of Relative Sea Level History, In Sea Level Rise, History and Consequences, B. C. Douglas, M. S. Kearney, S. P. Leartherman, Int Geophys Series, 75, pp. 65-95.

Peltier, W. R. (1998). Postglacial Variations in the Level of the Sea: Implications for Climate Dynamics and Solid-Earth Geophysics, Rev Geophys, 36, pp. 603-689.

Rignot, E., and R. H. Thomas (2002). Mass Balance of Polar Ice Sheets, Science, 297, pp. 1502-1506.

Sabadini, R., and B. L. A. Vermeersen (2002). Long-Term Rotation Instabilities of the Earth : A Reanalysis, pp. 51-67, In Ice Sheets, Sea Level and the Dynamic Earth, Geodyn Series 29.

Tamisiea, M. E., Mitovica J. X., G. A. Milne and J. L. Davis (2001). Global Geoid and Sea Level Changes Due to PresentDay Ice Mass Fluctuations, J Geophys Res, 106, pp. 3084930863. 